\title{
Experiências inovadoras de cuidado no Programa Saúde da Família (PSF): potencialidadese limites
}

Alice da Costa Uchôa ${ }^{1}$

UCHÔA, A.C. Innovative care experiences at Family Health Program (PSF): potential and limits. Interface - Comunic., Saúde, Educ., v.13, n.29, p.299-311, abr./jun. 2009.

Nowadays, PSF deals with practices from the biomedical model and with other practices that mark changes. This article approaches innovative care experiences based on a research study carried out in Natal, state of Rio Grande do Norte, between 2005 and 2007. It aimed to understand the full meaning of integrality, to discuss the role of professionals' creativity and sensitivity, and to analyze the possibilities of institutionalization and sustainability. Document analysis, semi-structured interviews with the professionals and observation of the experiences were used. The main integrality concepts that were found were: health promotion as a change in lifestyle, dialogic similarities between popular and scientific knowledge, the strengthening of popular participation and self-care. There was social recognition expressed by prizes, publications and plays. None of the projects had financial support. Therefore, it is concluded that such experiences had a vocation for promotion and care, although they lack political and financial sustainability.

Keywords: Innovation. Care. Integrality. Family Health Program. Health education.
Atualmente, o PSF convive com práticas do modelo biomédico e outras marcadoras de mudança. Este artigo aborda experiências inovadoras de cuidado baseada em pesquisa realizada em Natal no período de 2005 a 2007. Teve como objetivo compreender os sentidos da integralidade, discutir o papel da criatividade e sensibilidade dos profissionais e analisar as possibilidades de institucionalização e sustentabilidade. Utilizou análise documental; entrevista semi-estruturada com os protagonistas, observação das unidades e experiências. Dentre as concepções de integralidade encontradas destacam-se: promoção da saúde como mudança do estilo de vida; aproximações dialógicas entre saber científico e popular; fortalecimento da participação popular, auto-cuidado. Houve reconhecimento social expressos em ganho de prêmios, publicações e peças teatrais. Nenhum dos projetos contava com financiamento. Conclui-se que as experiências têm uma vocação para promoção e cuidado, mas ainda não têm sustentabilidade financeira e política.

Palavras-chave: Práticas inovadoras.

Cuidado. Integralidade. Programa Saúde da Família. Educação em saúde.
${ }^{1}$ Médica. Departamento de Saúde Coletiva, Universidade Federal do Rio Grande do Norte. Rua Romualdo Galvão, 3673 - H, 101, Lagoa Nova - Natal, RN, Brasil. 59.056-100

aliuchoa@hotmail.com 


\section{Introdução}

No Brasil, desde as duas últimas décadas, é premente a transformação da lógica predominante do setor saúde tendo em vista a superação do seu perfil excludente e os impactos da ampliação tecnológica da medicina no ato de cuidar.

O perfil excludente da atenção à saúde está mergulhado num contexto de exclusão social a que está submetida a maior parte da população, e que gera situações inéditas de fragilidade e vulnerabilidade da vida, da saúde e da sociedade. Na saúde, se evidencia: na persistência e expansão de velhas doenças; nas doenças evitáveis ou contornáveis; no advento de enfermidades emergentes; na violência e nos pânicos urbanos, entre outros. A maior parte dos agravos está inserida num ciclo vicioso de pobreza, isolamento e adoecimento. Se expressa num "sofrimento difuso" ou "mal-estar difuso" que corresponde a um conjunto de síndromes e sinais mal definidos, e, problemas psicossociais, como estresse, depressão, angústia, entre outros (Luz, 2003; Valla, 1999). Constitui o amálgama do "malestar social" causado pela "crise da medicina", quando, mesmo diante das possibilidades abertas pela tecnologia, ela não tem conseguido dá respostas satisfatórias às demandas de sofrimento da maior parte da população (Luz, 2003).

Em relação à ampliação das bases tecnológicas da biomedicina, os efeitos positivos e negativos já são relativamente bem conhecidos. De um lado, são inegáveis seus avanços: na ampliação da diagnose; na precocidade e amplitude da intervenção terapêutica, no aumento da eficácia e eficiência e segurança de muitas decisões; na melhora do prognóstico e da qualidade de vida dos pacientes em uma série de problemas de saúde traduzidos como doença. Do outro, temos: a autonomização dos exames complementares; a excessiva compartimentalização dos pacientes em órgãos; as intervenções excessivas; os aumentos dos custos da assistência; a insuficiente atenção aos aspectos psicossociais e culturais do adoecimento insurge-se como limitante às suas potencialidades (Uchôa, Camargo Jr, 2008; Ayres, 2005; 2000; Luz, 2004; Uchoa, 2003, 1994; Camargo Jr, 2003, 2002, 1997; Martins, 1999).

Schraiber (1997) denomina "crise de confiança" um sentimento social de insegurança quanto à adequação moral e técnica da biomedicina. Chama atenção para a progressiva incapacidade da assistência à saúde se tornar ao mesmo tempo racional e sensível no atendimento das necessidades de saúde das pessoas, e, sobretudo, no reconhecimento dos seus limites.

Ayres et al. (2005) consideram o ponto central da crise da medicina o afastamento progressivo de ambas as dimensões - arte e ciência - dos projetos existenciais de felicidade que lhes conferem sentido. A avaliação da adequação ou não dos procedimentos técnicos exige uma indagação constante sobre em que contexto e com que finalidade estes procedimentos são aplicados. Considera o cuidado, e não a cura, como central.

Gadamer (1991) apreende o cuidado como um encontro, uma interação entre quem cuida e quem são cuidados. Guiado por uma "práxis" ou "saber prático", não constrói objetos, mas sim sujeitos que são criados no mundo e voltados para ele. No campo da saúde, deve ter a intenção ética emancipatória de ampliar e qualificar o cuidado para além do saber-fazer científico-tecnológico, concebido como um procedimento sistemático e universal prévio ao ato de interação. O espaço relacional entre sujeitos cria um saber preocupado com a totalidade do outro, onde se destaca a necessidade do diálogo entre o saber biomédico centrado em evidências clínicas e epidemiológicas e outros saberes.

Para Foucault (1985), na civilização ocidental moderna, a categoria do "cuidado de si" é definida como um movimento de construção, manutenção e transformação das identidades dos indivíduos, transformando-se em "tecnologias do si". Nesse processo, é imperativo descobrir o sentido do saber, do sentir e da vivência do outro, e abranger o entendimento das linguagens culturais e afetivas dos distintos sujeitos. Esta troca implica a valorização do conhecimento cognitivo e afetivo, da intuição e da sensibilidade própria e do outro, ampliando o diálogo e o vínculo entre o sujeito promotor e aquele que é alvo dos cuidados.

Como afirmam Machado, Pinheiro e Guizardi (2004), a produção do cuidado representa um dos maiores desafios à organização dos serviços públicos de saúde, pois coloca questões que ultrapassam a competência técnico-científica em que se fundamenta o modelo biomédico. 
Luz (2005) chama atenção para o surgimento de novas práticas de saúde distintas tanto das racionalidades médicas quanto das práticas terapêuticas. O caráter inovador das práticas de saúde na sociedade civil é atribuído, não ao ineditismo, mas à revitalização de algumas práticas que foram "postas à sombra" em consequência de valores hegemônicos do capitalismo, como o individualismo e a competição desenfreada pelo sucesso. Estas "novas práticas" estão referenciadas no paradigma da "vitalidade", e não no da "saúde e doença". São associadas à "tríade beleza, vigor e juventude", traduzidas na boa forma (fitness) ou "beleza das formas", no bem-estar (wellness) ou no "estar bem consigo mesmo", no estar "harmonizado". Compreendem uma multiplicidade de ações que vão desde atividades físicas mais hards (fisiculturismo, musculação, aeróbica, entre outras) àquelas mais leves (dança de salão, música, teatro, artes plásticas, entre outras). Não devem ser pensadas a partir de um bloco monolítico de sentidos relacionados apenas à referida tríade, e sim a partir de uma teia de significados, incluindo a prevenção dos agravos e a promoção da saúde, na medida em que os padrões sociais de relações subjacentes, como empatia, colaboração, cordialidade, vão formando uma rede de "solidariedades focais", decisivas para o cuidado.

O estudo de Machado, Pinheiro e Guizardi (2004) toma, como objeto, "novas" formas de cuidado (práticas e saberes populares) e sua associação com o tratamento médico tradicional em serviços públicos do Rio de Janeiro. Estas práticas são definidas como ações voltadas à qualidade de vida que não demandem intervenção medicamentosa, levando às transformações de comportamento individual e coletivo.

A insuficiência dos modos tradicionais de apreensão e respostas aos processos de adoecimento está nas bases conceituais da reforma da atenção básica expressas no Programa de Saúde da Família (PSF). Este representa a resposta da atual política brasileira a um conjunto de contradições da sociedade e do sistema de serviços.

O PSF vem se revelando como uma nova base de articulação, promovendo a entrada de novos cenários, sujeitos e linguagens no âmbito da atenção à saúde. Destaca-se a ênfase dada aos aspectos da promoção da saúde, vulnerabilidade social e os elementos contextuais, político e organizacionais do modelo assistencial, reforçando a necessidade de interação entre diferentes campos de conhecimento, que incorpora novos objetos e tecnologias. Para reconstrução das práticas de saúde que possam ser traduzidas como cuidado, é exigida a ampliação dos horizontes da racionalidade científica que orienta as práticas (Ayres et al., 2005).

Pressupõe a incorporação de "tecnologias leves" (Franco et al., 2003), que se materializam em práticas relacionais como: acolhimento, vínculo, responsabilização, autonomia, e qualidade da atenção, que conformam a integralidade do cuidado (Souza et al., 2008; Campos, 2003; Paim, 2002).

Nesta perspectiva, pode-se pensar o PSF como um espaço aberto para a construção do cuidado orientado por um novo pensar e agir, um saber prático, uma ação dialógica na afirmação de Ayres (2005). O cuidado reposicionado como um valor, uma ação integral que tem significados e sentidos voltados ao direito do ser. A integralidade é abordada como uma construção coletiva que passa a ganhar forma e expressão no espaço do encontro dos diferentes sujeitos implicados (Pinheiro, 2007).

Partindo destes pressupostos, este artigo discute as contribuições de um conjunto de experiências que sinalizam para o avanço das tecnologias do cuidado no PSF. A pesquisa que originou o artigo teve como objetivo avaliar as potencialidades e os limites destas práticas inovadoras. Com base na percepção dos profissionais sobre as experiências vivenciadas, especificamente destinou-se a: compreender se elas são orientadas pela integralidade do cuidado; avaliar o papel da criatividade e sensibilidade dos profissionais, bem como a sustentabilidade destas práticas.

É importante que se explicite o entendimento de inovação, visto que abrange diferentes significados. O mais comum equivale à novidade e incorporação de novas técnicas aplicadas à análise da produção e disseminação de conhecimento e tecnologias A reflexão aqui adotada tem como base o conceito de inovação "emancipatória" ou "edificante", trazido por Santos, nas obras Um discurso sobre as ciências (1987), Introdução a uma ciência pós-moderna (1989) e Pela mão de Alice (1997). Santos diferencia a inovação técnica, ou regulatória, da "emancipatória" ou edificante A primeira deixa de fora quem inova, e, portanto, não é afetado por ela. Há uma separação entre fins e meios, em que se escamoteiam os 
eventuais conflitos e silenciam as definições alternativas. Inovar seria produzir o "novo" em relação ao preexistente para produzir uma mudança descontextualizada e o não-desenvolvimento de novas relações entre o ser, o saber e o agir (Santos, 1997, 1989, 1987).

A inovação edificante parte da idéia de que suas bases epistemológicas estão alicerçadas no caráter emancipatório e argumentativo da "ciência emergente". Opõe-se às clássicas dicotomias entre ciências naturais/ciências sociais, teoria/prática, sujeito/objeto, conhecimento/realidade. Busca maior comunicação e diálogo com os saberes locais e com os diferentes atores, e realiza-se em um contexto que é histórico e social. Tem sempre "[...] lugar numa situação concreta em que quem aplica está existencial, ética e socialmente comprometido com o impacto da aplicação". Não há separação entre fins e meios, uma vez que a ação incide sobre ambos, pois "[...] os fins só se concretizam na medida em que discute os meios adequados à situação concreta", como afirma Santos (1989, p.158).

Ao trazerem esta definição ao objeto do estudo, as experiências inovadores de cuidado representam um conjunto de práticas que sinalizam para a quebra do paradigma biomédico na direção do cuidado. Ou seja, são práticas diferenciadas (arte, teatro, folclore, atividades físicas, entre outros) das experiências que acontecem pragmaticamente nas equipes do PSF. São (re)significadas por estes profissionais como práticas destinadas a abordar situações de saúde pelas quais são responsáveis. Assim, são invenções assentadas em contextos locais específicos, na criatividade e envolvimento pessoal e compromisso, e no caráter não rotinizado, burocratizado ou protocolizado.

\section{Metodologia}

O método escolhido foi o de Estudo de Caso (Yin, 2005), e utilizou várias fontes de evidências, triangulando técnicas (análise documental e entrevistas); e beneficiou-se do desenvolvimento prévio de proposições teóricas para conduzir a coleta e a análise dos dados.

A pesquisa desenvolveu-se em Natal, Rio Grande do Norte. O mapeamento das experiências foi realizado no período de março a junho de 2005. Foram utilizadas, como fonte de informação: a descrição das experiências desenvolvidas pelo PSF no memorial das II Mostras Nacional e Estadual de Saúde da Família, realizada em junho e setembro de 2004, e as informações dos gestores municipais e do PSF. Os critérios de inclusão foram: o projeto em curso, desenvolvido de forma autoral por profissionais ou equipe, cujas ações fossem voltadas a resolver situações de saúde e que não faziam parte das já existentes no território, preconizadas nos protocolos dos grupos tradicionais do PSF.

Foram utilizadas as seguintes técnicas de pesquisa: análise documental, observação estruturada, observação simples e entrevista semiestruturada com profissionais.

A análise documental foi realizada de março a dezembro de 2005, e teve, como objetivo, contextualizar as inovações do cuidado. As fontes utilizadas foram: documentos institucionais (memorial da II Mostra Nacional de Produção em Saúde da Família do Ministério da Saúde e os projetos municipais como Projeto PROESF, Relatório de Gestão, Relatório Mapeando Qualidade de Vida, entre outros) e relatos das experiências (projetos formais das experiências junto à SMS, papers, artigos e monografias).

Para o contexto, contemplaram-se os seguintes aspectos: socioeconômicos e sanitários, modelo de atenção e gestão, áreas e ações/projetos estratégicos. As análises dos relatos e projetos tiveram, como direcionamento, os seguintes pontos: histórico, justificativa, objetivos, categorias de profissionais envolvidos, público alvo, estratégias de ação, atividades realizadas, parcerias e resultados encontrados.

Para observação estruturada, foram incluídas as Unidades de Saúde da Família (USF) que desenvolviam as atividades em 2006. O roteiro de observação continha os seguintes itens: tempo de funcionamento, atuação e número de famílias por equipes; localização; condições sanitárias e ambientais; ambiência para acolhimento; planejamento e ações de prevenção e promoção, controle social; organização por área/ microárea; equipamentos, medicamentos e insumos básicos para atendimento; ações programáticas; praticas alternativas com a população, protocolos, visitas domiciliares; referência e contratransferência; evidências de demanda reprimida. Para as experiências, a observação foi simples e os dados foram registrados em diário de campo. Procedeu-se, em média, a três observações por experiência. Algumas fotos foram disponibilizadas pelos profissionais entrevistados. 
Foram realizadas 22 entrevistas semiestruturadas, gravadas nos locais das práticas inovadoras (unidades, clubes, praças, entre outros), com duração média de uma hora e meia cada. O critério para inclusão dos profissionais foi pertencer às equipes que protagonizavam as experiências de forma direta $e$ contínua, se responsabilizando por seu desenvolvimento. Nas entrevistas foram abordados os seguintes aspectos: o contexto de emergência da experiência; motivações; objetivos; descrição das atividades; relação entre profissionais envolvidos direta e indiretamente no trabalho em equipe e com as práticas usuais de atenção; modo de inserção dos usuários e profissionais; relação com outras práticas da unidade; percepção dos usuários, profissionais e instâncias gestoras sobre as influências na atenção à saúde prestada; tipos de apoio recebidos, financiamento, visibilidade e impactos.

O processo de análise utilizou a metodologia de Bardin (1979). A primeira etapa foi a pré-análise, que se apoiou numa leitura flutuante das transcrições e anotações empreendidas pelos entrevistadores, buscando como a criatividade e sensibilidade dos profissionais ia modelando e conformando as práticas do cuidado no cotidiano institucional. Seguiu-se a descrição analítica, onde, com base no referencial teórico e em diversas leituras do material obtido (imersão), organizou-se o material em categorias: Contexto de emergência (idéia inicial, objetos, motivação e desenvolvimento); concepções de integralidade do cuidado; sustentabilidade (institucionalização/formalização; participação da comunidade e apoio político; financiamento, visibilidade e impacto).

A pesquisa foi aprovada pelo Comitê de Ética em Pesquisa da Universidade Federal do Rio Grande do Norte, com o número de protocolo 100/06 - CEP/UFRN

\section{Resultados e discussão}

Será apresentada uma síntese do contexto e parte dos resultados da triangulação (análise documental, entrevistas e observação das experiências) por categoria de análise.

\section{Contexto sociossanitário e as experiências inovadoras}

No município do Natal, as experiências inovadoras do cuidado (Rodas de Conversa, Promovendo a Saúde Através da Arte, Atividades Físicas com Idosos de Santarém, Biodança, Valorizarte, Pastoril do Peixe Boi Encantado e Guarartes), surgidas a partir de 2002-2003, acompanharam a expansão e a distribuição do PSF em áreas de maior vulnerabilidade epidemiológica e social.

A ocupação dos bairros onde eram desenvolvidas as experiências representa o que Santos, Souza e Silveira (1994) chamam de "especializações de territórios": espaços metropolitanos diferenciados e fragmentados, cujo processo de periferização corresponde, antes de qualquer coisa, ao empobrecimento da população. A tendência de expansão em direção aos limites municipais e o progressivo esvaziamento das áreas com ocupação mais antigas e de melhor infraestruturada, e a afluência para regiões onde não há infraestrutura e serviço adequados, onde predominam os piores índices de qualidade, representam, para a gestão do sistema de saúde, um grande desafio na busca da equidade.

Particularmente, dois bairros eram palcos de um número razoável de ações governamentais e nãogovernamentais voltadas ao combate da violência e da exclusão social por meio do resgate da cultura local, da arte, e da educação. Estas ações buscavam contribuir para a construção da cidadania e mudança da imagem do bairro - traduzidas numa sensação de orgulho cívico, pertencimento e melhoria da qualidade de vida, que inspiraram a valorização do folclore no Pastoril do Peixe-Boi Encantado e Guarartes.

Nos projetos estudados, estes circuitos e padrões de sociabilidade eram variados: ressignificação das brincadeiras infantis efetuadas em propostas pedagógicas nas Rodas de Conversa; grupos de teatro e teatro de fantoches no Promovendo à Saúde Através da Arte; grupo de apoio com atividades físicas, dança e lazer na Atividade Física com Idosos e Biodança, e artesanato, ofício, folclore e geração de renda no Valorizarte. 


\section{Antecedentes, motivações, objetivos e desenvolvimento das experiências}

As distintas motivações dos profissionais passavam, em diferentes graus, pela percepção da necessidade de se ampliarem as ações de promoção à saúde para além das tradicionais atividades de criação de grupos e práticas educativas centrada em palestras, como exemplifica o depoimento:
A idéia do trabalho comunitário Valorizarte surgiu da vivência das pessoas que tinham muita habilidade tanto no tocante ao usuário do serviço que não eram devidamente valorizado e os funcionários do posto de saúde que, quando chegam na hora do almoço, estavam fazendo trabalhos manuais, como ponto cruz, sabonetes... Então, eu observei... como enfermeira, tinha chegado há pouco tempo... que havia a necessidade de se fazer trabalho diferenciado que não fossem apenas palestras educativas, mas que fizesse um trabalho voltado para a arte e que essa arte fosse instrumento terapêutico e também formação de renda para as pessoas. (Profissional Valorizarte)

Percebe-se uma mobilização destes profissionais na tentativa de superar a sensação de impotência diante da multiplicidade de determinantes sociais do processo saúde e doença, e que o trabalho desenvolvido no contexto familiar e social próprio do usuário torna-se mais explícito do que ocorre na "metragem limitada do consultório" (Profissional Rodas de Conversa). Diante de situações adversas e complexas de adoecimento, pobreza e exclusão vivenciadas pelas comunidades, o recurso à arte, cultura, atividades físicas e laborativas, lazer e socializações apareceram como alternativas para romper com a relativa passividade dos profissionais e usuários em relação à manutenção do modelo medicalizante, dentro da estratégia da Saúde da Família.

Dentre os objetivos, foram ressaltados: o vínculo, a participação da comunidade, o trabalho em equipe e novas práticas de educação em saúde (Rodas de Conversa); a mudança do comportamento assistencialista de profissionais e usuários, e o trabalho em equipe (Promovendo à Saúde Através da Arte); a prevenção de desequilíbrios psicológicos e debilidade física (Atividade Física com Idosos); o estímulo do potencial humano e a autoestima de usuários, profissionais e comunidade como forma de prevenção de agravos em saúde mental; doenças cronicodegenerativas, e inclusão no mercado (Valorizarte); mudança de hábitos de vida, com atividades físicas e lazer para prevenção das complicações da hipertensão e diabetes (Biodança); interação de profissionais, usuários e comunidade para estimular a criatividade e práticas de educação em saúde (Guarartes).

\section{Concepções sobre integralidade}

Em todas as experiências, as concepções acerca da integralidade destacaram, ora, seu caráter pedagógico de cunho emancipátorio, com vistas à melhoria da qualidade de vida e saúde - dentro do marco conceitual e analítico da promoção da saúde - ora como integralidade do cuidado (ampliação da escuta, do acolhimento e do vínculo) - ora como ambos. Chamam atenção as nuances e matizes que adquirem em cada experiência singular.

As Rodas de Conversa conferiram maior ênfase à educação em saúde como espaço dialógico e solidário, com: ampliação da escuta, participação dos usuários, e relações mais próximas entre profissional e serviço, numa abordagem do campo da educação popular em saúde como potencializadora do cuidado.

Todos os profissionais que atuam como mediadores percebem a importância do corpo-a-corpo, da troca de valores e saberes, da força das palavras e gestos, espontâneos ou não intencionais, para a promoção individual e coletiva de saúde, de uma maneira leve, alegre, e ampliada no sentido de estender a atenção além da metragem limitada de um consultório. (Profissional Rodas de Conversa)

[...] Uma estratégia de inovação para promoção de saúde (Saúde da Família) que visava fortalecer os princípios do SUS exigia uma maneira diferente, interativa de perceber os determinantes do processo de trabalho na saúde e que pudesse valorizar e potencializar o 
vínculo e a co-responsabilização entre equipe de saúde e usuários. (Profissional Roda de Conversa)

Para Vasconcelos (1998), este campo, na medida em que problematiza e cria contextos de diálogo entre os atores envolvidos, propicia a construção e difusão de um novo conhecimento que, ao mesmo tempo, inova em relação ao conhecimento crítico em saúde, e aponta para caminhos institucionais e organizativos mais adequados à superação dos problemas de saúde.

O projeto Promovendo à Saúde Através da Arte, com sua visão holística (biopsicossocial) trouxe o foco para os aspectos relacionais entre profissionais, e entre estes e usuários. A arte seria um lócus de transformação das práticas dos profissionais na direção da humanização e do vínculo:
Acredito na possibilidade de transformação das práticas de saúde a partir de reflexões acerca dos sentimentos que permeiam as relações e a expressão desses sentimentos como um caminho para a efetivação de vínculos [...] A música e a arte de representar proporcionam encontros de subjetividades, reflexões e criações surpreendentes. Tivemos momentos valiosos para o corpo e para a mente. (Promovendo a Saúde Através da Arte)

Na encenação, buscava-se o trabalho em equipe. Reviver nas cenas do teatro as práticas da USF representava refletir criticamente sobre as subjetividades na construção do vínculo, da escuta, do respeito.

Próximo a este arcabouço, situa-se o Pastoril do Peixe-Boi Encantado, cuja noção de qualidade de vida estava relacionada à idéia de vitalismo ou energia vital, presentes em práticas de saúde que não são propriamente afeitas ao paradigma biomédico. Estava muito alicerçada na autonomia de usuários e profissionais, na autoestima, na valorização do grupo e da comunidade.

O Pastoril, quando ele se apresenta, a gente sente uma explosão de vida naquelas pessoas mais idosas, é como ressurgisse aquela vitalidade. Quando elas estão dançando, elas conseguem movimentos tão perfeitos que às vezes a gente fica olhando e pensando: "meu Deus, isso é dona Fulana?" [...] São atores sociais estabelecendo um novo modo de fazer saúde, com arte, dançando, bailando, redescobrindo seu corpo, tendo participação ativa na construção da sua própria saúde e construindo vínculo. (Profissional Pastoril)

Muitas destas características são semelhantes às descrições de "novas práticas de saúde" originadas na sociedade civil. Luz (2005) chama atenção para os padrões sociais de relações que lhe são subjacentes - como empatia, colaboração, cordialidade - e vão formando uma rede de "solidariedades focais", decisivas para o cuidado.

As dimensões de felicidade, bem-estar, lazer, presentes nas Atividades Físicas com Idoso e na Biodança, também trabalham as subjetividades, particularmente entre as usuárias idosas, abrindo oportunidades para a criação de laços de sociabilidade. Esta concepção aparece mais ligada à noção de mudanças de estilo de vida, autocuidado, com vistas à prevenção de fatores de risco, sendo complementares às ações individuais.

[...] conhecendo as condições de vida, o nível de stress e de ociosidade ao quais as pessoas do bairro são submetidas, na maioria mulheres idosas, percebo que estas pessoas precisavam de um grupo, um espaço para desenvolver práticas de socialização, de conversa e que trabalhe também o físico e a educação em saúde, que funcione como uma terapia de grupo. (Profissional Biodança)

Este direcionamento da experiência traz, ao espectro do cuidado, a noção de grupo como apoio social. Como afirmam Sluzki (1997), Lacerda e Valla (2004), o apoio social promove o sentimento de pertencimento onde a ressonância das dores dos outros ajuda a buscar possíveis soluções até então não pensadas, potencializando o próprio cuidado. Para Rudio (1998), as intervenções junto aos diferentes 
grupos programáticos se nortearam pelo incentivo à autonomia e responsabilização do paciente pelo seu próprio estado de saúde. Ainda segundo o autor, acredita-se que o sujeito, ao tomar para si o poder de controlar sua própria vida, adquire a possibilidade de se desenvolver em uma direção que seja congruente às suas potencialidades pessoais, respondendo às demandas externas.

O Valorizarte é também demarcado por uma visão holística com o resgate da arte, talento e habilidades voltadas à superação da centralidade da medicalização. Também é marcante uma configuração de saberes técnicos, populares e artísticos, cuja posição de ensinar não está necessariamente vinculada ao profissional e, de aprender, aos usuários - ambos exercem os dois papéis de acordo com as respostas pretendidas, e com os potencias de cada um dos polos. Um diferencial está na grande preocupação de se conquistar a confiança e possibilitar alternativas às condições concretas e objetivas de vida. Entre as alternativas às condições de vida, o projeto destaca estratégias de preparação para inserção no mercado informal ou formal de trabalho, mediante aprendizado de um ofício ou profissão, artesanato e expressões artísticas. Estas práticas não se relacionam diretamente ao paradigma da doença, mas incorporam a noção de saúde como direito de cidadania.

\begin{abstract}
A inércia e o sedentarismo contribuem de forma acentuada para o agravamento das [...] doenças crônicas degenerativas. $\mathrm{O}$ isolamento social e a baixa auto-estima predispõem o indivíduo às doenças mentais. A saúde em seu conteúdo holístico, não se restringe às [...] consultas médicas e terapêutica puramente química [...] O bem estar físico, mental e social pode ser obtido através de atividades lúdicas e laborais que envolvem o potencial oriundo da própria comunidade. Valorizar as artes e os artesãos, estimulando-se a disseminarem o seu saber cultural à comunidade, é uma forma de resgatar a cidadania e melhorar a qualidade de vida dos comunitários. (Profissional Valorizarte)
\end{abstract}

A noção de cidadania e participação comunitária no escopo desta concepção de saúde e da resposta da atenção à mesma é mais explícita neste projeto. De acordo com Bodstein (2005), a literatura atual acerca da avaliação em promoção da saúde, a efetividade das iniciativas de melhoria da saúde e da qualidade de vida implicam um profundo envolvimento dos atores e da população beneficiária. Este envolvimento seria mais efetivo na medida em que considerasse o processo de (re) construção de identidades culturais, o fortalecimento da cidadania e das redes sociais locais.

O projeto Guarartes aproxima-se tanto dos projetos que buscam, na educação em saúde, uma ferramenta voltada para a mudança com o uso de outras linguagens que não as da transmissão linear do conhecimento (Rodas) quanto das que recorrem à arte e à cultura (Valorizarte, Promovendo à Saúde Através da Arte, Pastoril). Porém, com temáticas diretamente relacionadas com a prevenção de fatores de risco e promoção da saúde.

A gente faz o teatro, procuramos o médico, se for um assunto que a gente não tem conhecimento então ele vai dar os tópicos e a gente apronta aquela peça. Como o de mama, vocês sabem que mama para falar para os idosos é difícil de elas aceitarem a fazer o autoexame. A gente passou nas casas deixamos os convites e a maioria veio para fazer o autoexame aqui e a gente viu que pela peça o que a gente passou foi muito bom para eles. (Profissional Guarartes)

\title{
Sustentabilidade: institucionalização formalização e financiamento
}

Em relação à institucionalização e formalização, pode-se afirmar que todas as iniciativas haviam sido institucionalizadas, ou seja, faziam parte do escopo das atividades das USF(s) de forma continuada, e foram formalizadas junto à SMS por meio de projetos específicos. Dois projetos contavam com a adesão de todos os profissionais (Valorizarte e Santarém), nos demais a participação foi variável. Considerando o total de profissionais das sete USF(s) (204), chega a 75\% (154). Se forem levadas em conta as especificidades de algumas atividades (talentos), a adesão pode ser até maior que a participação. 
As Rodas de Conversa foram absorvidas como metodologia usual das práticas de educação em saúde e como modo de planejar a unidade. A adesão dos profissionais foi parcial. Alguns resistiram à proposta dos idealizadores da experiência de substituir as tradicionais palestras de educação em saúde pela abordagem dialógica das Rodas de Conversa. Contudo, entre os profissionais que aderiram, a flexibilidade da metodologia inovadora provocou grande disponibilidade para sua realização. Assim, conforme as equipes, as rodas ocorriam de forma exclusiva, sobreposta ou simultânea às palestras. É importante atentar para o fato de que, como a participação dos usuários não era vinculada à equipe, e sim à unidade, a exemplo de sala de espera, campanhas, em algum momento qualquer usuário da USF podia se tornar beneficiário. Em outro momento, passou a fazer parte da estruturação do pré-natal no chamado "Nove Luas". Como uma abordagem já disponibilizada no campo da educação, inclusive em saúde, a metodologia foi adotada por outras instâncias da SMS, sem que isso leve à leitura de uma disseminação do projeto.

A Atividade Física com Idosos e a Biodança representavam atividades qualitativamente diferentes, mas dentro do espectro de promoção e prevenção de determinado protocolo já existente na USF, como o HIPERDIA. Em outros termos, embora integrados ao protocolo preconizado pelo MS e adotado, houve adição de ações derivadas da criatividade de alguns profissionais. Esta integração leva à percepção de que todos os profissionais da USF participavam direta ou indiretamente (consultas, orientações, palestras, entre outros). A instituição de um rodízio, a incorporação de instrutores de outra secretaria municipal para a prática de artesanato, que exigia um saber técnico específico, possibilitou a atuação das diferentes equipes. Já na Biodança, era necessária capacitação ou formação, como condição para o papel de instrutor ou organizador, que estava nas mãos de um só profissional. A inserção dos demais era pontual em atividades de lazer e, mesmo assim, mais restrita aos agentes.

Todas as demais experiências que envolviam arte e resgate cultural foram implantadas na interface serviço-usuário, e não integradas a determinado grupo ou programa. Sua realização exigia um conjunto de ações prévias (cursos, ensaios, preparação de material, entre outras), e durante sua realização, que acabava trazendo uma outra dinâmica à organização do trabalho. Embora nenhuma contasse com apoio de todas as categorias e de todos os profissionais, eram perceptíveis rearranjos com apoio da direção, como folgas, substituições. Entre os profissionais percebe-se adesão solidária, com substituição em tarefas, incorporação ao agendamento e planejamento da unidade. Na totalidade dos projetos, a institucionalização contou com apoio do nível distrital e da SMS (estímulo para relatos e realização de eventos com divulgação, premiação, entre outros), com maior ou menor grau de dificuldade. Observouse iniciativa dos distritos de congregar as diferentes USF (s) que realizavam projetos semelhantes, "rompendo" os muros de cada unidade em particular.

Pode-se afirmar que, se vistos pelo ângulo da promoção, prevenção e humanização, estes e todos que apontassem nesta direção estariam contemplados nas linhas prioritárias da proposta política da gestão municipal de saúde presentes nos planos e projetos da gestão desde 2003, mais acentuadamente a partir de 2006, como explicitaram os documentos analisados.

Todavia, as falas dos profissionais elucidam que o apoio estava condicionado à não diminuição da produtividade dos atendimentos "reconhecidos" pelo Sistema de Informação da Atenção Básica (SIAB). Como consequência, os rearranjos, diante da ampliação do leque de serviços ofertados, acabaram levando à sobrecarga de volume de trabalho, de horas trabalhadas e de procedimentos não diretamente computados. Em alguns momentos, os entrevistados revelaram "não valorização", "não reconhecimento" e, até mesmo, "discriminação", em meio a "avanços e retrocessos". Estes últimos são traduções de resistência de alguns profissionais e ou dirigentes às novas práticas.

Estamos vivenciando um cansaço e desmotivação. É como se estivéssemos "remando contra a maré". Estreamos um espetáculo em julho desse ano que contou a história do PSF na unidade, mas, tivemos que ensaiar finais de semana, feriados e agilizar outras coisas pendentes no horário noturno. (Profissional Promovendo à Saúde Através da Arte) 
Um importante agravante é que a base de sustentação financeira das iniciativas é bastante frágil. Embora a exigência do projeto formal se destinasse, entre outras coisas, à solicitação de recursos necessários, em nenhum dos casos o financiamento pela SMS foi confirmado. Contudo, deve-se assinalar a construção de galpões, em algumas unidades, para atividades coletivas e fornecimento de materiais educativos ligados aos programas, que nem sempre eram adequados às novas práticas. Todos os projetos lançavam mão de recursos financeiros doados, sobretudo, pelos próprios profissionais (isolados ou em cota) e usuários, para confecção de cenários e figurinos, material para os cursos e oficinas de artesanato.

Apenas a Atividade Física com Idosos afirmou ter convênio com outra secretaria (Assistência Social), que resultava no pagamento de lanche e disponibilidade de instrutores mediante cadastro de, no máximo, trinta idosos. Como os custos eram maiores, tanto pelo número de participantes quanto da necessidade de algum equipamento, o restante era financiado pelo organizador. Alguns projetos obtiveram apoio da universidade e de outros patrocinadores eventuais, mas estes foram datados e sem garantias de continuidade.

As estratégias do grupo Valorizarte tinham um pouco mais de organicidade, com uma imagemobjetivo de empreendimento (cooperativa) autossustentável. Contavam com recursos humanos (instrutores) e locais de diferentes organizações sociais do bairro. Mas o material para produção era também fornecido por profissionais e usuários. A consecução da meta exigia um aporte de recursos superiores aos disponibilizados.

\section{Sustentabilidade: participação comunitária e apoio político}

O modo como cada projeto foi concebido é revelador do envolvimento ora dos usuários ora da comunidade. Conforme descrito, a perspectiva do Valorizarte explicava o trabalho em parceria com organizações sociais locais do tipo cooperativo e escolas profissionalizantes. O papel transmissor de conhecimento e habilidades estava diretamente relacionado ao domínio técnico e ao talento que existisse tanto entre profissionais como usuários.

Nos grupos que utilizavam as artes cênicas e/ou folclóricas, o envolvimento comunitário se dava por meio de articulações com grupos artísticos locais e alguma capacitação em teatro, mamulengo, entre outros. Uma das USF's já havia formado anteriormente um grupo de teatro de agentes comunitários, "Trupe da Fantasia", que, no transcurso da experiência, incorporava profissionais e usuários de outras USF(s), dando origem à companhia "Ser Humano". A revitalização do Pastoril envolvia outras organizações e grupos artísticos já atuantes na comunidade. A constituição de grupo de teatro conferiu, ao Guarartes e aos demais, uma mobilidade por meio da qual a encenação dos espetáculos em diferentes locais ampliava, para além da área de abrangência, os beneficiários. As atividades voltadas aos grupos com práticas de exercícios e lazer e as Rodas não envolviam, diretamente, as organizações da comunidade.

Todavia, não se deve deixar de registrar que a institucionalização das experiências fazia com que, de algum modo, houvesse interação com outros atores pertencentes aos apoios sociais e conselhos gestores das unidades. Mas não se observou apoio político partidário. Se o número de beneficiários indiretos era grande, o direto estava limitado em torno de trinta por projeto, e o de usuários ou comunitários envolvidos na condução era menos expressivo.

\section{Sustentabilidade: visibilidade}

As experiências realizadas em Natal adquiriram intensa visibilidade nos cenários nacional, estadual e municipal, com premiações em eventos que avaliam justamente os avanços do PSF na direção da conversão do modelo assistencial. Fomentaram debates acadêmicos em artigos, trabalho de conclusão de curso e congressos. Ganharam espaço na mídia. Ocuparam teatros da cidade e, mesmo, espaço na internet. Foram objetos de avaliação nas unidades, nos distritos e na SMS, e consideradas como impactantes, sobretudo, no vínculo, na humanização, na promoção da saúde, no autocuidado e na melhoria da qualidade de vida dos usuários e, até, dos profissionais. 


\section{Conclusões}

A integralidade emerge tanto como articulação entre promoção e assistência dentro do paradigma da promoção da saúde, quanto como espaço de ampliação da escuta, do acolhimento e do vínculo (cuidado como valor) de forma articulada. Promoção da Saúde e Cuidado, ainda que partam de arcabouços conceituais diferenciados, são vivenciados, pelo atores, de forma sinérgica, frente à necessidade de responder questões pertinentes à complexidade do adoecimento e à busca por respostas.

Foram significativas as concepções de promoção, como: mudança do estilo de vida; aproximações dialógicas entre saber científico e popular; fortalecimento da participação comunitária (resgate da cultura popular e cidadania); protagonismo (autocuidado e estratégias de superação da exclusão social). Entretanto, todas tinham como meta: a interação com a comunidade, o vínculo, o acolhimento, a responsabilização como estratégia de melhoria das condições de saúde.

Reconhece-se, nas experiências estudadas, um forte apelo à saúde como um meio para o desenvolvimento humano (bem-estar, felicidade, vitalidade, prazer) e o autocuidado, conferindo um sentido positivo diferenciado de ausência de doença. Este, por sua vez, era colocado como condição para saúde.

A legitimidade das mesmas apresentou graus variados, desde restrita aos grupos de usuários na perspectiva de educação, informação e divulgação, até parcerias com organizações comunitárias, caracterizando participação social com maior impacto na promoção da saúde. Também não houve apoio político de instâncias formais do SUS (Conselhos Municipais) ou blocos partidários. Contudo, mesmo a participação comunitária sendo ainda restrita, denota a porosidade necessária das iniciativas oficiais aos diferentes saberes e interesses da população.

As experiências são fortemente ancoradas na sensibilidade e criatividade dos profissionais, que atuam como mediadores entre o serviço e a comunidade estabelecendo pontes, criando condições para a ocorrência de contatos e interações entre campos/contextos culturais e sociais distintos. Se, de um lado, pode-se afirmar que as inovações fomentaram o diálogo entre a racionalidade biomédica e outros saberes e práticas sociais, do outro, promoveram o convívio, muitas vezes conflituosos, entre diferenciadas lógicas. A ocorrência paradoxal de estímulo aos projetos e a exigência de produtividade, a falta de financiamento e poucos casos de participação comunitária fazem com que, mesmo não marginalizadas, tenham sua sustentabilidade comprometida.

Garantir a continuidade destas experiências é apostar num meio de engajamento coletivo para integrar ações dispersas e criar sinergias no sentido de se buscarem soluções alternativas para diferentes momentos do trabalho em saúde, desenvolver o sentimento de pertencimento de mobilização dos protagonistas. Contudo, deve-se refletir sobre: a persistência de grande demanda para o atendimento, sobrecarga de trabalho, falta de condições estruturais, entre outros fatores, e fazer os ajustes no próprio PSF, cujo horizonte é condicionado pela dinâmica dos projetos tecnoassistenciais em disputa.

\section{Referências}

AYRES, J.R.C.M. Cuidado e reconstrução das práticas de saúde. In: MINAYO, M.C.S.; COIMBRA JR., C.E.A. (Orgs.). Críticas e atuantes: ciências sociais e humanas em saúde na América Latina. Rio de Janeiro: Fiocruz, 2005. v.1. p.91-108.

Cuidado: tecnologia ou sabedoria prática? Interface - Comunic., Saude Educ., v.4, n.6, p.117-120, 2000.

AYRES, J.R.C.M. et al. O conceito de vulnerabilidade e as práticas de saúde: novas perspectivas e desafios. 3. reimp. In: CZERESNIA, D.; FREITAS, C.M. (Orgs.). Promoção da saúde: conceitos, reflexões, tendências. 3.ed. Rio de Janeiro: Fiocruz, 2005. p.117-40. 
BARDIN, L. Análise de conteúdo. Lisboa: Edições 70, 1979.

BODSTEIN, R.C.A. Institucionalização da avaliação como estratégia de fortalecimento da atenção básica. Bol. Abrasco, v.94, p.14-15, 2005.

CAMARGO JR., K.R. Sobre palheiros, agulhas, doutores e o conhecimento médico: o estilo de pensamento dos clínicos. Cad. Saude Publica, v.19, n.4, p.1163-74, 2003.

The thought style of physicians: strategies for keeping up with medical knowledge. Soc. Stud. Sci., v.32, n.6, p.827-55, 2002.

A biomedicina. Physis, v.7, n.1, p.45-68, 1997.

CAMPOS, G.W.S. Saúde Paidéia. São Paulo: Hucitec, 2003.

FRANCO, T.B. et al. O trabalho em saúde: olhando e experienciando o SUS no cotidiano. São Paulo: Hucitec, 2003.

FOUCAULT, M. História da sexualidade 3: o cuidado de si. 3.ed. Rio de Janeiro: Graal, 1985.

GADAMER, H.G. Verdad y método: fundamentos de una hermenêutica filosófica. 4.ed. Salamanca: Sígueme, 1991.

LACERDA, A.; VALLA, V.V. As práticas terapêuticas de cuidado integral à saúde como proposta para aliviar o sofrimento. In: PINHEIRO, R.; MATTOS, R.A. (Orgs.). Cuidado: as fronteiras da integralidade. Rio de Janeiro: Hucitec/Abrasco, 2004. p.91-2.

LUZ, M.T. Novas práticas em saúde coletiva. In: MINAYO, M.C.S. (Org.). Críticas e atuantes: ciências humanas e sociais em saúde na América Latina. Rio de Janeiro: Fiocruz, 2005. p.33-46.

Fragilidade social e busca do cuidado na sociedade civil de hoje. In: PINHEIRO, R.; MATTOS, R. A. (Orgs.). Cuidado: as fronteiras da integralidade. Rio de Janeiro: Hucitec/Abrasco, 2004. p.9-20.

Novos saberes e práticas em Saúde Coletiva: estudo sobre práticas corporais e saúde. São Paulo: Hucitec, 2003.

MACHADO, F.R.S.; PINHEIRO, R.; GUIZARDI, F.L. As novas formas de cuidado integral nos espaços públicos de saúde. In: PINHEIRO, R.; MATTOS, R.A. (Orgs.). Cuidado: as fronteiras da integralidade. Rio de Janeiro: Hucitec/Abrasco, 2004. p.57-74.

MARTINS, A. Novos paradigmas e saúde. Physis, v.9, n.1, p.83-112, 1999.

PAIM, J.S. Modelos assistenciais: reformulando o pensamento e incorporando a proteção e a promoção da saúde. In: Saúde: política e reforma sanitária. Salvador: Cooptec/ISC, 2002. p.367-81.

PINHEIRO, R. Cuidado como valor: um ensaio sobre o (re)pensar e a ação na construção das práticas de saúde. In: PINHEIRO, R; MATTOS, R.A. (Orgs.). Razões públicas para a integralidade: o cuidado como valor. Rio de Janeiro: CEPESC-IMS/ UERJ/Abrasco, 2007. p.15-28.

RUDIO, F.V. Diálogo maiêutico e psicoterapia existencial. São José dos Campos: Novos Horizontes, 1998.

SANTOS, B.S. Pela mão de Alice: o social e o político na pós-modernidade. 4.ed. São Paulo: Cortez, 1997.

Introdução a uma ciência pós-moderna. Rio de Janeiro, Graal, 1989.

. Um discurso sobre as ciências. Porto: Afrontamento, 1987.

SANTOS, M.; SOUZA, M.A.A.; SILVEIRA, M.L. (Orgs.). Território, globalização e fragmentação. São Paulo: Hucitec/Ampur, 1994. 
SCHRAIBER, L.B. No encontro da técnica com a ética: o exercício de julgar e decidir no cotidiano do trabalho em saúde. Interface - Comunic., Saude, Educ., v.1, n.1, p.12338, 1997.

SLUZKI, C.E. A rede social na prática sistêmica. São Paulo: Casa do Psicólogo, 1997.

SOUZA, E.C.F. et al. Acesso e acolhimento na atenção básica: uma análise da percepção dos usuários e profissionais de saúde. Cad. Saude Publica, v.24, suppl.1, p.s100-s110, 2008.

UCHÔA, S.A.C. Os protocolos e a decisão médica: evidências ou vivências? 2003. Tese (Doutorado em Saúde Coletiva) - Instituto de Medicina Social, Universidade Estadual do Rio de Janeiro, Rio de Janeiro. 2003.

Erro médico: de senhor da vida a senhor da morte, um estudo sobre a representação do erro na prática médica. 1994. Dissertação (Mestrado em Ciências Sociais) - Programa de Pós-Graduação em Sociologia, Universidade Federal da Paraíba, João Pessoa. 1994.

UCHÔA, A.C.; CAMARGO JR., K. Os protocolos e a decisão médica: medicina baseada em vivências e ou evidências? Cienc. Saude Colet.. Disponível em: <http://

www.abrasco.org.br/cienciaesaudecoletiva/artigos/artigo_int.php?id_artigo=318>. Acesso em: 25 nov. 2008

VALLA, V.V. Educação popular, saúde comunitária e apoio social numa conjuntura de globalização. Cad. Saude Publica, n.15, p.7-14, 1999.

VASCONCELOS, E.M. Educação popular com instrumento de reorientação das estratégias de controle das doenças infecciosas e parasitárias. Cad. Saude Publica, n.14, p.39-57, 1998.

YIN, R.K. Estudo de caso: planejamento e métodos. 3.ed. Trad. Daniel Grassi. Porto Alegre: Bookman, 2005.

UCHÔA, A.C. Experiencias innovadoras de cuidado en Programa de Salud de la Familia (PSF): potencialidades y límites. Interface - Comunic., Saúde, Educ., v.13, n.29, p.299-311, abr./jun. 2009.

Actualmente el PSF convive con prácticas del modelo bio-médico entre otras que marcan cambios. Este artículo expone experiencias de cuidado innovadoras con base en investigación realizada en Natal, Brasil, durante el período de 2005 a 2007. Ha tenido como objetivo comprender los sentidos de integralidad, discutir el papel de la creatividad y de la sensibilidad de los profesionales y analizar las posibilidades de institucionalización y sustentabilidad. Utiliza el análisis documental, entrevista semiestructurada con las protagonistas, observación de las unidades y experiencias. Entre las concepciones de integralidad encontradas se destacan la promoción de la salud como cambio de estilo de vida, aproximaciones dialógicas entre saber científico y popular, fortalecimiento de la participación popular, auto-cuidado. Hubo reconocimiento social expresado en premios, publicaciones y obras teatrales. Ninguno de los proyectos contaba con financiación. Se concluye que las experiencias tienen vocación para promoción y cuidado pero aún no tienen sustentabilidad financiera y política.

Palabras clave: Prácticas innovadoras. Cuidado. Integralidad. Programa de Salud Familiar. Educación en salud. 